\title{
Caracterización de la pandemia de gripe A H1N1 2009 en Navarra
}

\section{The 2009 H1N1 influenza pandemic in Navarre, Spain}

\author{
J. Castilla ${ }^{1,2}$, J. Morán ${ }^{3}$, M. Fernández-Alonso ${ }^{4}$, V. Martínez Artola ${ }^{5}$, M.J. Zamora ${ }^{6}$, \\ A. Mazón ${ }^{7}$, C. Fernández ${ }^{5}$, M. García Cenoz ${ }^{1,2}$, F. Elía ${ }^{3}$, G. Reina ${ }^{4}$, E. Salcedo ${ }^{5}$, \\ F. Irisarri, ${ }^{1,2}$ A. Barricarte, ${ }^{1,2}$ Red de Médicos Centinela y Red de Vigilancia \\ Epidemiológica y Microbiológica de la gripe de Navarra
}

\section{RESUMEN}

Fundamento. Describir la actividad gripal durante la pandemia de 2009-2010 en Navarra y compararla con la de temporadas anteriores.

Métodos. Se han analizado los casos de gripe notificados en atención primaria y todas las confirmaciones virológicas realizadas en pacientes de atención primaria y en hospitales de Navarra entre las semanas 21 de 2009 y 20 de 2010.

Resultados. El virus de la gripe A (H1N1) 2009 se detectó en Navarra entre las semana 23 de 2009 a la 2 de 2010, periodo en el que se registraron 39 casos con diagnóstico médico de síndrome gripal por 1.000 habitantes. El umbral epidémico se superó en dos periodos, con un pico en julio y otro mayor en noviembre. La mayor incidencia se alcanzó en niños de 5 a 14 años (121 por mil), seguidos por el grupo de menores de 5 años. Se produjeron 224 hospitalizaciones (36 por 100.000 habitantes) con confirmación de gripe A H1N1 2009, 8\% de ellos requirieron ingreso en unidades de cuidados intensivos y hubo cuatro defunciones ( 0,6 por 100.000 habitantes). La tasa de hospitalizaciones fue mayor en niños menores de 5 años (163 por 100.000 habitantes), mientras que la probabilidad de derivación a cuidados intensivos aumentó con la edad.

Conclusión. A pesar de no haber dispuesto de una vacuna específica hasta que la temporada estaba muy avanzada, el virus de gripe A (H1N1) 2009 produjo una onda gripal en rangos similares a los de otras temporadas y su repercusión en hospitalizaciones y casos graves fue moderada.

Palabras clave. Gripe. Pandemia. Salud pública. Vigilancia epidemiológica.

An. Sist. Sanit. Navar. 2010; 33 (3): 287-295

\begin{abstract}
Background. To describe influenza activity during the 2009-2010 pandemic in Navarre and compare it to previous seasons.
\end{abstract}

Methods. An analysis was made of all influenza-like illness cases reported in primary care and all the virological confirmations made in patients in primary care and in hospitals of Navarre between week 21 of 2009 and week 20 of 2010 .

Results. Influenza 2009 H1N1 virus was detected in Navarre between week 23 of 2009 and week 2 of 2010 , a period when 39 medically diagnosed cases of influenza-like illness per 1,000 inhabitants were registered. The epidemic threshold was surpassed in two periods, with a peak in July and a greater one in November. The greatest incidence was reached in children aged between 5 and 14 years (121 per thousand), followed by the group of under fives. There were 224 hospitalisations (36 per 100,000 inhabitants) with confirmation of influenza 2009 H1N1 virus, $8 \%$ of whom required admission to intensive care units and there were four deaths ( 0.6 per 100,000 inhabitants). The rate of hospitalisation was greater amongst children under five (163 per 100,000 inhabitants), while the probability of referral to intensive care increased with age.

Conclusion. In spite of not having a specific vaccine available until the season was very well advanced, influenza 2009 H1N1 virus produced a wave of cases with similar incidence to those of other seasons and its repercussion in hospitalisations and serious cases was moderate.

Key words. Influenza. Pandemic. Public health. Epidemiological Surveillance.

\section{Correspondencia \\ Jesús Castilla Catalán \\ Instituto de Salud Pública \\ Leyre, 15 \\ 31003 Pamplona \\ E-mail: jcastilc@navarra.es}

\section{Financiación}

Esta actividad ha sido financiada parcialmente por el European Center for Disease Prevention and Control (Proyecto I-MOVE) y el Instituto de Salud Carlos III (GR09/0028 y PS09/01179). 


\section{INTRODUCCIÓN}

El virus de la gripe ocasiona anualmente epidemias estacionales con amplia extensión mundial. Se estima que entre el 5 y el $20 \%$ de la población tiene gripe cada año y esta cifra aumenta cuando se produce una pandemia ${ }^{1}$. La gripe afecta principalmente a niños y adultos jóvenes, pero sus peores consecuencias ocurren en personas con enfermedades crónicas y en mayores, en los cuales la gripe puede causar complicaciones y mortalidad $^{1-5}$. La principal intervención de salud pública para controlar la difusión y las consecuencias de la gripe en la población es la vacunación anual de los grupos de población con mayor riesgo ${ }^{6}$.

En abril de 2009 se detectó por primera vez la afectación en humanos por una variante del virus de la gripe A (H1N1) 2009 de origen porcino $^{7-9} \mathrm{y}$, en poco tiempo, se extendió por el mundo, llevando a la Organización Mundial de la Salud a declarar la situación de pandemia. Este virus presentaba importantes diferencias con respecto a otros virus de gripe A (H1N1) 2009 que habían circulado en temporadas previas, lo que hizo sospechar de la ausencia de protección cruzada por infecciones gripales previas ni por la vacuna de gripe estacional $^{10}$. A diferencia de otras ondas de gripe estacional, el virus A (H1N1) 2009 circuló ampliamente durante varios meses antes de que pudiésemos disponer de una vacuna específica.

En el presente estudio se describe, mediante indicadores clínicos y virológicos, la actividad gripal durante la temporada 2009-2010 en Navarra y se compara con la de temporadas anteriores.

\section{MATERAL Y MÉTODOS}

El síndrome gripal es una enfermedad de declaración obligatoria individualizada en Navarra. La notificación se efectúa de forma automatizada desde el programa informático de historia clínica, que está implantado en todos los centros de atención primaria y consultorios de la red asistencial pública, y se complementa con la declaración del resto de los dispositivos asistenciales. Se utiliza la definición de síndrome gripal según la segunda versión de la Clasificación Internacional de Atención Primaria ${ }^{11}$. De cada caso se recoge la fecha de diagnóstico, el sexo, la edad y la zona básica asistencial.

Desde 2003 existe una Red de Médicos Centinela de Atención Primara para la vigilancia de la gripe, que en 2009 se amplió a 60 médicos de familia, 12 pediatras y 2 médicos de residencias geriátricas, que cubrieron unas 110.000 personas, con buena representatividad de toda la población. En esta red se aplica la definición europea de síndrome gripal que requiere el comienzo súbito de síntomas, la presencia de al menos un síntoma general (fiebre, cefalea o malestar general) y la presencia de al menos un síntoma respiratorio (tos, disnea, dolor de garganta). En estos casos se registra la sintomatología y las complicaciones. De una muestra de los casos, seleccionados con un criterio sistemático, se tomó en la consulta, previo consentimiento informado verbal, frotis nasofaríngeo para diagnóstico virológico. Las notificaciones de la red centinela de Navarra se integran con las redes centinela de España y de Europa (European Influenza Surveillance Scheme) para la comparación con otras comunidades autónomas y países.

Desde la declaración de la alerta pandémica se sistematizó en todos los hospitales la vigilancia epidemiológica de casos graves de posible etiología gripal. A todos los pacientes con enfermedad respiratoria aguda que ingresaron y a todos los casos graves o con factores de riesgo atendidos en urgencias se les tomó un frotis nasofaríngeo para estudio de virus de la gripe.

Tanto los frotis de la red de médicos centinela como los de hospitales fueron procesados en uno de los dos laboratorios de referencia (Complejo Hospitalario de Navarra y Clínica Universidad de Navarra) mediante RT-PCR (reverse-transcriptasepolymerase-chain-reaction) y cultivo viral. Los aislados fueron caracterizados por técnicas de inmunofluorescencia o RT-PCR para gripe A (subtipos H1 y H3) y gripe B. 
Desde junio de 2009 se aplicó a todos los frotis la técnica de RT-PCR en tiempo real para la detección del virus A (H1N1) 2009. Una muestra representativa de los virus aislados fue enviada al laboratorio de gripe del Centro Nacional de Microbiología para genotipado y caracterización.

Como denominadores de las tasas se utilizaron los datos de la población de $\mathrm{Na}$ varra según el padrón del Instituto Nacional de Estadística a enero de 2009.

En el presente trabajo consideramos todos los casos clínicos de gripe notificados en atención primaria, los casos de gripe ingresados y las confirmaciones en laboratorio realizadas entre las semanas 21 de 2009 y la 20 de 2010.

\section{RESULTADOS}

\section{Incidencia de síndromes gripales}

En el periodo entre las dos temporadas de gripe de 2009 (semana 21 a 39) se notificaron 4.389 casos de síndrome gripal en
Navarra ( 7 por mil habitantes) y entre las semanas 40 de 2009 y 20 de 2010 se notificaron otros 19.616 casos (32 por mil), lo que suma un total de 24.005 casos de síndrome gripal y una tasa de 39 casos por mil habitantes. Entre el 12 al 25 de julio de 2009 se registró un pico en la incidencia que superó ligeramente el umbral epidémico y remitió en las semanas siguientes. El grupo de edad más afectado fue el de 15 a 44 años (59\% de los casos), seguido por el de 5 a 14 años (19\%). En octubre la incidencia de gripe volvió a aumentar, alcanzando el pico en la segunda semana de noviembre con 667 casos por 100.000 habitantes, para retornar por debajo del umbral epidémico desde mediados de diciembre (Fig. 1). Esta vez fueron los niños el grupo de edad más afectado. La vacuna específica frente al virus A (H1N1) 2009 comenzó a administrarse en la semana 46 , coincidiendo con el comienzo en el descenso de la incidencia aunque, debido al tiempo necesario para generar respuesta inmune, no cabría esperar su efecto antes de la semana 47.

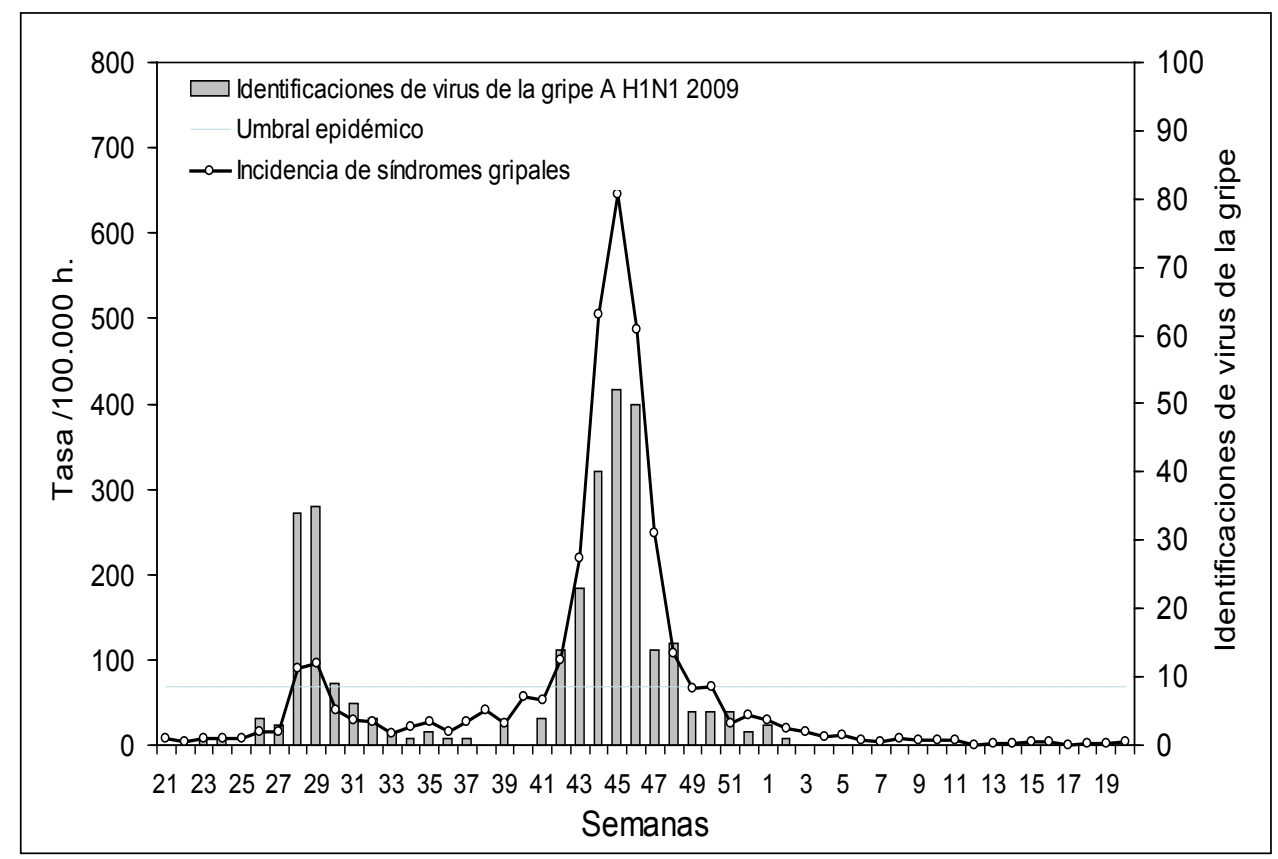

Figura 1. Incidencia semanal de síndromes gripales y detecciones de virus de la gripe en la red de médicos centinela de Navarra en la temporada 2009-2010. 
La incidencia acumulada de gripe durante la temporada pandémica estuvo dentro del rango de las cinco temporadas anteriores (17 a 42 casos por mil) y la ubicación temporal de la onda gripal, aunque adelantada respecto a lo que suele ser habitual, alcanzó el pico en la semana 45 , al igual que había ocurrido en la temporada 2003-2004.
Considerando todo el periodo no se observaron diferencias en la incidencia por sexos. La mayor tasa de incidencia de síndromes gripales se detectó en niños de 5 a 14 años (121 por mil), seguidos a gran distancia por los niños menores de 5 años (72 por mil). El $41 \%$ de los casos de síndrome gripal tenían menos de 15 años y el $84 \%$ menos de 44 años (Tabla 1).

Tabla 1. Incidencia de síndromes gripales e identificaciones de virus de la gripe en pacientes de la red centinela. Navarra, semanas 21 de 2009 a 20 de 2010.

\begin{tabular}{lcccccc}
\hline & \multicolumn{2}{c}{$\begin{array}{c}\text { Incidencia de síndromes } \\
\text { gripales }\end{array}$} & \multicolumn{3}{c}{$\begin{array}{c}\text { Frotis nasofaríngeos de la red } \\
\text { de médicos centinela }\end{array}$} \\
\hline & Casos & $\%$ & $\begin{array}{c}\text { Tasa por 1.000 } \\
\text { hab. }\end{array}$ & $\begin{array}{c}\text { Analizados } \\
\mathbf{n}^{\mathbf{0}}\end{array}$ & $\begin{array}{c}\text { Positivos a } \\
\text { gripe, } \mathbf{n}\end{array}$ & $\%$ \\
\hline Sexo & & & & & & \\
$\quad$ Hombre & 11.953 & 50 & 39 & 441 & 179 & 41 \\
$\quad$ Mujer & 12.052 & 50 & 39 & 403 & 161 & 40 \\
Edad, años & & & & & & \\
0-4 & 2.420 & 10 & 72 & 32 & 6 & 19 \\
$5-14$ & 7.502 & 31 & 121 & 114 & 75 & 66 \\
$15-44$ & 10.195 & 42 & 38 & 499 & 204 & 41 \\
$45-64$ & 3.214 & 13 & 21 & 154 & 48 & 31 \\
65 y más & 674 & 3 & 6 & 45 & 7 & 16 \\
Total & 24.005 & 100 & 39 & 844 & 340 & 40 \\
\hline
\end{tabular}

En los casos de gripe notificados por los médicos centinela se registraron los síntomas. Entre los casos de niños menores de 15 años confirmados en laboratorio los síntomas más frecuentes fueron la fiebre, el malestar general y la afectación de vías respiratorias altas. En adultos también destacó la tos como síntoma muy frecuente. La disnea fue inusual entre los casos diagnosticados en atención primaria (Tabla 2).

Tabla 2. Síntomas en los casos confirmados de gripe A (H1N1) 2009.

\begin{tabular}{|c|c|c|c|c|}
\hline \multirow[t]{2}{*}{ Síntomas } & \multicolumn{2}{|c|}{$\begin{array}{l}\text { Niños (0-14 años) } \\
\quad \mathrm{N}=81\end{array}$} & \multicolumn{2}{|c|}{$\begin{array}{c}\text { Adultos ( } \geq 15 \text { años) } \\
N=268\end{array}$} \\
\hline & № & $\%$ & № & $\%$ \\
\hline Comienzo súbito & 72 & 89 & 212 & 79 \\
\hline Fiebre & 81 & 100 & 266 & 99 \\
\hline Escalofríos & 65 & 80 & 210 & 78 \\
\hline Malestar general & 75 & 93 & 263 & 98 \\
\hline Cefalea & 68 & 84 & 227 & 85 \\
\hline Artralgia/mialgias & 55 & 68 & 231 & 86 \\
\hline Tos & 57 & 70 & 246 & 92 \\
\hline Dolor de garganta & 64 & 79 & 196 & 73 \\
\hline Disnea & 4 & 5 & 23 & 9 \\
\hline Afectación de vías altas & 73 & 90 & 238 & 89 \\
\hline
\end{tabular}




\section{Vigilancia virológica de la gripe}

Los primeros aislamientos del nuevo virus A (H1N1) 2009 en Navarra fueron realizados, por la red de médicos centinela, en junio de 2009 en personas que habían adquirido la infección en otras comunidades autónomas, y en julio se constató un aumento de casos con evidencia de transmisión autóctona. Durante el verano (semana 20 a la 39) se tomaron 282 frotis nasofaríngeos en la red de médicos centinelas, de los cuales 107 (38\%) resultaron positivos a gripe A (H1N1) 2009. Desde la semana 40 de 2009 hasta la 20 de 2010 se tomaron otros 562 frotis, de los cuales 233 (41\%) resultaron positivos para el virus A (H1N1) 2009. La red centinela detectó circulación de gripe A (H1N1) 2009 de forma prácticamente continua desde la semana 23 de 2009 hasta la semana 2 de 2010 , pero desde entonces hasta el final de la temporada no volvió a detectar presencia de virus de la gripe en Navarra (Fig. 1). En dos momentos el porcentaje de frotis que se confirmó para gripe A (H1N1) 2009 superó el 50\%; esto ocurrió en las semanas 28 y 29 , y entre las semanas 43 y 48 de 2009 . Todas las cepas caracterizadas en esta temporada han sido idénticas a A/California/07/2009 (H1N1).

La identificación del virus de la gripe fue más frecuente en los frotis tomados en niños de 5 a 14 años (66\%), y menos frecuente en menores de 5 años (19\%) y en mayores de 65 años (16\%). El porcentaje de confirmación fue similar en hombres y mujeres (Tabla 1). En algunas de las muestras negativas a virus de la gripe tomadas a pacientes con síndrome gripal se analizó la presencia de otros virus respiratorios, encontrándose virus Parainfluenza en distintos momentos de la temporada, principalmente en septiembre y octubre. El virus respiratorio sincitial se detectó mayormente en niños entre noviembre y febrero. En los meses de verano se detectó esporádicamente presencia de enterovirus, adenovirus y metapneumovirus.

\section{Incidencia de casos hospitalizados con confirmación de gripe}

En el periodo de circulación de la gripe pandémica se confirmaron 224 casos de gripe A (H1N1) 2009 en personas que requirieron ingreso hospitalario. Esto supuso una tasa de hospitalización de 36 por 100.000 habitantes; 9 ingresos por cada mil casos de síndrome gripal diagnosticados. De los ingresados, 18 (8\%) causaron estancia en unidades de cuidados intensivos y 4 casos fallecieron. La letalidad entre el total de casos de gripe fue de 17 por 100.000 , pero entre los casos ingresados en unidades de cuidados intensivos se elevó al 22\% (Tabla 3). Los ingresos se distribuyeron a lo largo de las semanas en las que se detectó la circulación del virus de la gripe, coincidiendo los momentos con mayor número de hospitalizaciones con los de máxima incidencia de síndromes gripales. No obstante, también se produjeron varios ingresos hospitalarios y en unidades de cuidados intensivos cuando la incidencia de síndromes gripales se mantenía en niveles muy bajos (Fig. 2).

Tabla 3. Casos de gripe con confirmación por laboratorio con ingreso hospitalario.

\begin{tabular}{|l|c|c|c|c|c|c|c|c|c|}
\hline & \multicolumn{3}{|c|}{ Casos hospitalizados } & \multicolumn{3}{c|}{$\begin{array}{c}\text { Casos ingresados en unidades de } \\
\text { cuidados intensivos }\end{array}$} & \multicolumn{3}{c|}{ Defunciones } \\
\hline $\begin{array}{c}\text { Edad, } \\
\text { años }\end{array}$ & № & $\%$ & $\begin{array}{c}\text { Tasa por } \\
\mathbf{1 0 0 . 0 0 0} \\
\text { habitantes }\end{array}$ & № & $\begin{array}{c}\text { \% de los } \\
\text { hospitalizados }\end{array}$ & $\begin{array}{c}\text { Proporción } \\
\text { de casos, } \\
\text { por 1.000 }\end{array}$ & № & $\begin{array}{c}\text { \% de los ingresos } \\
\text { en Cuidados } \\
\text { Intensivos }\end{array}$ & $\begin{array}{c}\text { Tasa por } \\
100.000 \\
\text { habitantes }\end{array}$ \\
\hline $0-4$ & 56 & 25 & 167 & 0 & 0 & 0 & 0 & - & 0,0 \\
\hline $5-14$ & 30 & 13 & 48 & 0 & 0 & 0 & 0 & - & 0,0 \\
\hline $15-44$ & 64 & 29 & 24 & 9 & 14 & 0,9 & 2 & 22 & 0,7 \\
\hline $45-64$ & 47 & 21 & 31 & 7 & 15 & 2,2 & 1 & 14 & 0,7 \\
\hline 65 y más & 27 & 12 & 26 & 2 & 7 & 3,0 & 1 & 50 & 0,9 \\
\hline Total & 224 & 100 & 36 & 18 & 8 & 0,8 & 4 & 22 & 0,6 \\
\hline
\end{tabular}




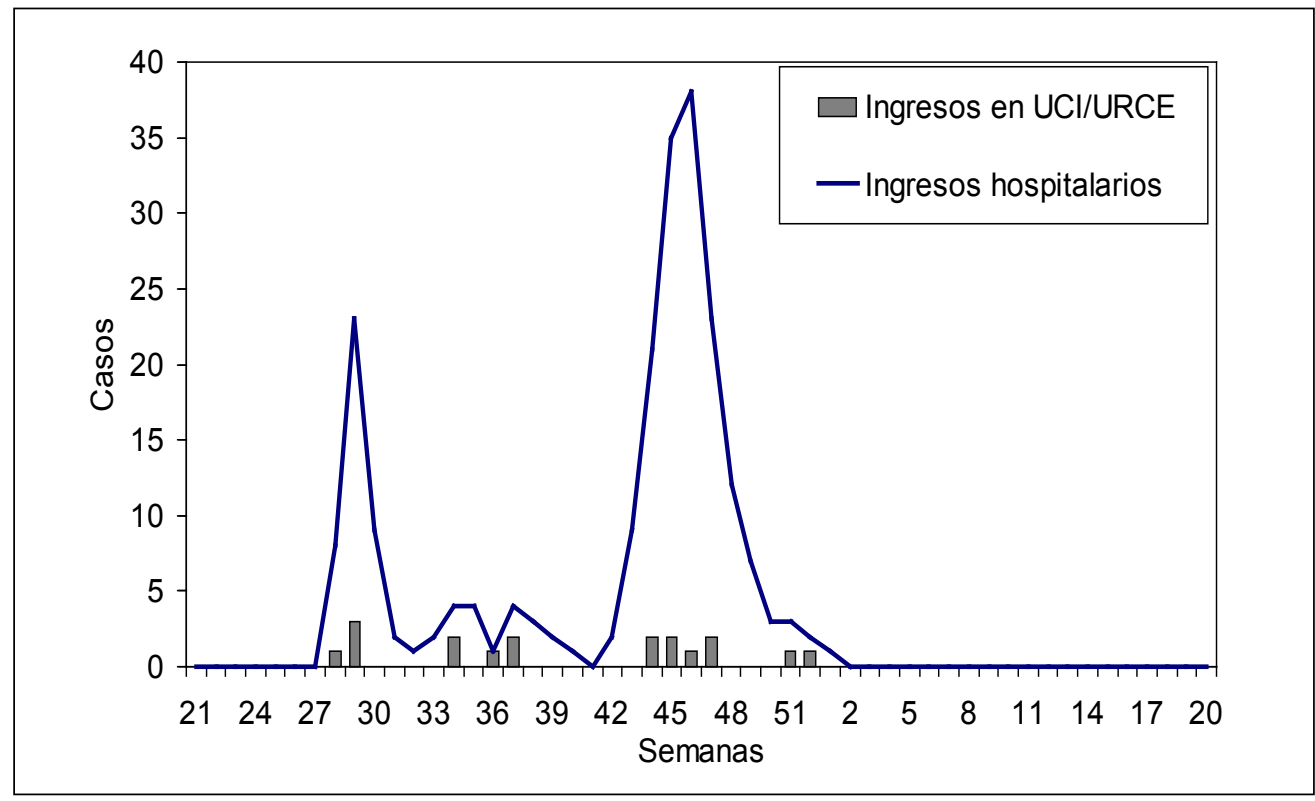

Figura 2. Ingresos hospitalarios e ingresos en unidades de cuidados intensivos (UCI/URCE) por semanas en pacientes con confirmación de gripe A (H1N1)2009. Temporada 2009-2010.

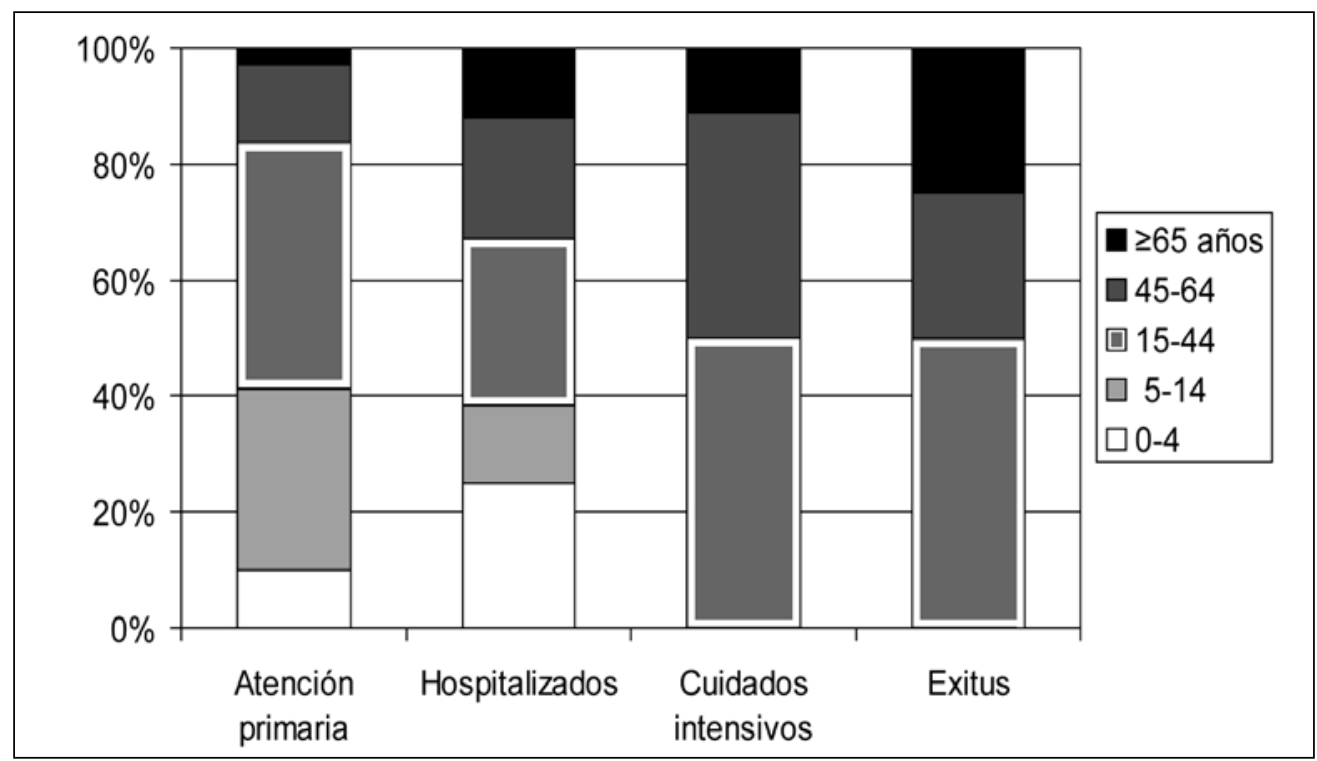

Figura 3. Distribución etárea de los casos de gripe en distintas situaciones.

El 25\% de los ingresos fueron en niños menores de 5 años, el $13 \%$ tenían ente 5 y 14 años, el $29 \%$ tenían entre 15 y 44 años, el $21 \%$ entre 45 y 64 años y el $12 \%$ tenían 65 años o más (Fig. 3). El 35\% de los ingresa- dos tenían alguna enfermedad crónica de base, otro $8 \%$ eran pacientes asmáticos, el $3 \%$ mujeres embarazadas, el $1 \%$ tenían obesidad mórbida, y el 52\% restante no refirió patología de base ni otras circunstancias 
de riesgo; un tercio de estos últimos eran niños menores de 5 años.

Los 18 casos que requirieron ingreso en unidades de cuidados intensivos tenían entre 15 y 81 años. Ocho tenían alguna patología crónica previa, dos tenían antecedente de asma, una era mujer embarazada y los 7 restantes (39\%) no tenían ninguna patología ni factor de riesgo conocido.

\section{DISCUSIÓN}

Durante la temporada gripal 2009-2010 se produjo en Navarra una onda gripal con dimensiones similares a las de otros años, en la que todas las identificaciones de gripe correspondieron al virus pandémico $\mathrm{A}$ (H1N1) 2009. Desde el punto de vista epidemiológico su comportamiento se mantuvo dentro de la variabilidad habitual en la gripe estacional, pero con algunas peculiaridades ${ }^{12}$. La gripe pandémica irrumpió en Navarra en forma de brote, en la segunda mitad de julio, que afectó principalmente a adultos jóvenes. Inicialmente la transmisión pudo verse favorecida por la gran concentración de personas de diversas procedencias con motivo de las fiestas de San Fermín ( 7 al 14 de julio) y por varios brotes en campamentos infantiles. También pudo verse algo magnificada por la búsqueda intensiva de casos en el contexto de la pandemia. En otros lugares se habían descrito anteriormente brotes esporádicos de gripe en verano ${ }^{13}$, que suelen tener curso autolimitado por las condiciones ambientales desfavorables para su propagación. A favor de estos argumentos están el que en dos semanas se retornase a niveles basales de incidencia y que en otras comunidades autónomas no se superase el umbral epidémico durante todo el verano ${ }^{14}$. La principal onda de gripe pandémica se produjo con la llegada del otoño y el retorno de la población a su actividad habitual.

También fue inusual la escasa incidencia en mayores, aún antes de disponer de una vacuna específica, lo cual se ha explicado por la posible protección cruzada por anticuerpos preexistentes adquiridos en exposiciones ocurridas décadas atrás ${ }^{15}$.
El comportamiento de la gripe pandémica presentó diferencias muy pronunciadas en función de la edad. La incidencia de gripe es habitualmente mucho mayor en niños que en adultos ${ }^{16}$, pero en la gripe pandémica este efecto ha sido aún más pronunciado. Esto ha hecho que la sobrecarga asistencial haya tenido mayor repercusión en las consultas de pediatría, tanto de atención primaria como de urgencias hospitalarias. Los niños de 5 a 14 años presentaron las mayores incidencias de enfermedad y los mayores porcentajes de identificación del virus de la gripe en nasofaringe. Los niños menores de 5 años generaron ingresos hospitalarios en mayor proporción. Sin embargo, los ingresos en cuidados intensivos y los fallecimientos se produjeron mayormente en adultos, coincidiendo con lo descrito en otros lugares ${ }^{17-18}$.

Esta temporada pandémica estuvo poco afectada por las vacunas. La mayoría de los estudios no atribuyen ningún efecto relevante a la vacuna estacional frente al virus pandémico ${ }^{19-20}$, algunos encuentran un efecto protector ${ }^{9,21}$, y otros la consideran de riesgo ${ }^{22}$. La vacuna pandémica llegó cuando la incidencia de gripe estaba descendiendo, por lo que su efecto en la difusión del virus habría sido en todo caso muy pequeño ${ }^{23}$.

La notificación de gripe en atención primaria y la vigilancia centinela existían previamente, lo que permitió disponer de datos de temporadas anteriores obtenidos con criterios comparables. ${ }^{16}$ En contraste con ello, durante la temporada 2009-2010 se realizó una búsqueda de casos en hospitales y confirmación de gripe por laboratorio mucho más intensa que en años precedentes, lo que limita la comparabilidad de estos datos con los de otras temporadas. En todo caso, el número de casos graves fue relativamente pequeño en comparación con algunas de las previsiones que se habían hecho ${ }^{24}$.

Con vistas al futuro queda demostrada la utilidad de disponer de sistemas de vigilancia consolidados que integren información epidemiológica y virológica y que mantengan criterios comparables entre regiones, países y a lo largo de los años ${ }^{14}$. La 
vigilancia centinela en atención primaria ya reúne estos criterios, y sería bueno mantenerla y complementarla con estrategias de vigilancia de la gripe en hospitales.

En la próxima temporada gripal 20102011 se considera probable que siga circulando el virus A (H1N1) 2009, y de hecho, la nueva vacuna de la gripe estacional lo incluye en su composición ${ }^{25}$. En todo caso, la experiencia epidemiológica de la temporada 2009-2010 es útil para prever su impacto y comportamiento en la población.

\section{Agradecimientos}

A todos los médicos declarantes del sistema de Enfermedades de Declaración Obligatoria y a todos los profesionales que colaboran en el circuito de esta información. Agradecemos su colaboración a Agurtzane Zabala y Edurne Garde.

\section{ANEXO}

Red de Médicos Centinelas de Gripe. I. Abad, J. Ágreda, P. Aldaz, E. Álvarez, J.J. Arana, I. Arceiz, E. Arina, M.D. Artajo, A. Arza, K. Ayerdi, B. Azagra, J. Baleztena, J. Bartolomé, C. Bernués, J. Berraondo, C. Bolea, A. Brugos, S. Buil, F. Calle, B. Cano, J.C. Cenoz, F. Cía, F. Cortés, C. Chérrez, B. Churío, E.M. Da Costa, J. De Prado, J. Díez Espino, M. Doiz, F.J. Escribano, M.J. Esparza, L. Fanlo, C. Fernández Alfaro, A. Fernández Urtasun, J. Gamboa, M.L. Garcés, P. González Lorente, N. Goñi, J. Guillén, M.J. Guillorme, J.O. Guiu, A. Gulina del Pueyo, J.C. Gurbindo, M.J. Guruchaga, J.A. Heras, M.S. Indurain, B. Iñigo, S.E. Juan Belloc, O. Lecea, M.P. León, J.J. Longás, A. Martínez Díaz, C. Maurer, Mª Monge, M. Moreno, U. Navarro, F.J. Orozco, M. Orte, J. Palau, F. Pérez Afonso, M. L. Pérez Del Valle, P. Pérez Pascual, M.A. Pous, A. Prado, A. Puig Arrastia, E. Ridruejo, M.A. Rodríguez González, A. Roig, M.A. Roncal, I. Ruiz Puertas, H. Selles, M.A. Senosiain, J. Sola, M. Sota, P. Uhalte, J. Ulibarri, M.E. Ursua, I.A. Urtasun, M.J. Vigata, M.T. Virto, J.M. Vizcay, M. Zabalza, J. Zubicoa.

Vigilancia Epidemiológica de Gripe: A. Barricarte, J. Castilla, M. García Cenoz, F. Irisarri, J. Morán, A. Salaberri, F. Elía, J. Chamorro, J. Gost, M.J. Zamora, F. Reparaz, N. Álvarez.

Vigilancia Microbiológica de Gripe: E. Salcedo, V. Martínez Artola, M. Fernández Alonso, G. Reina, C. Fernández, A. Mazón, A. Gil-Setas, A.I. Álvaro, A. Petit.

\section{BIBLIOGRAFÍA}

1. GlezEn WP. Serious morbidity and mortality associated with influenza epidemics. Epidemiol Rev 1982; 4: 25-44.

2. Thompson WW, Shay DK, Weintraub E, Brammer L, Cox N, ANDERson LJ et al. Mortality associated with influenza and respiratory syncytial virus in the United States. JAMA 2003; 289: 179-186.

3. Thompson WW, Shay DK, Weintraub E, Brammer L, BRIDGES CB, Cox NJ et al. Influenza-associated hospitalizations in the United States. JAMA 2004; 292: 1333-1340.

4. Nicholson KG, Wood JM, ZAmbon M. Influenza. Lancet 2003; 362: 1733-1745.

5. Reichert TA, Simonsen L, Sharma A, Pardo SA, FEDSON DS, MlLLeR MA. Influenza and the winter increase in mortality in the United States, 1959-1999. Am J Epidemiol 2004; 160: 492-502.

6. Fiore AE, Shay DK, Broder K, Iskander JK, Uyeki TM, Mootrey G et al. Prevention and control of seasonal influenza with vaccines: recommendations of the Advisory Committee on Immunization Practices (ACIP) 2009. MMWR Recomm Rep 2009; 58: 1-52.

7. New influenza A/H1N1 virus: global epidemiological situation, June 2009. Wkly Epidemiol Rec 2009; 84: 249-257.

8. Novel Swine-Origin Influenza A (H1N1) Virus Investigation Team. Emergence of a novel swine-origin influenza A (H1N1) virus in humans. N Engl J Med 2009; 360: 2605-2615.

9. Echeverría-Zuno S, Mejía-Aranguré JM, MarObeso aJ, Grajales-Muñiz C, Robles-Pérez E, GonZÁLEZ-LEÓN $P$ et al. Infection and death from influenza A H1N1 virus in Mexico: a retrospective analysis. Lancet 2009; 374: 2072-2079.

10. Garten RJ, Davis CT, Russell CA, Shu B, LindsтRом S, Balish A et al. Antigenic and genetic characteristics of swine-origin 2009 A (H1N1) influenza viruses circulating in humans. Science 2009; 325: 197-201.

11. ICPC-2. International Classification of Primary Care, 2nd edn. Oxford: Oxford University Press, 1998.

12. Lessler J, Reich NG, Cummings DAT and the New York City Department of Health and Mengal Hygiene Swine Influenza Investigation Team. Outbreak of 2009 pandemic influenza A (H1N1) at a New York city school. N Engl J Med 2009; 361: 2628-2636.

13. Zhao H, Joseph C, Phin N. Outbreaks of influenza and influenza-like illness in schools in England and Wales, 2005/06. Euro Surveill. 2007 May 1; 12 (5): E3-4. 
14. Larrauri Cámara A, Jiménez-Jorge S, Simon MénDEZ L, DE Mateo OnTañón S, en representación del Sistema de Vigilancia de Gripe en España (SVGE). Vigilancia de la pandemia de gripe (H1N1) 2009 en España. Rev Esp Salud Pública $2010 ; 84 ; 569-588$.

15. Hancock K, Vegullla V, Lu X, Zhog W, Butler EN, Sun $\mathrm{H}$ et al. Cross-reactive antibody responses to the 2009 pandemic H1N1 influenza virus. N Engl J Med 2009; 361: 1945-1962.

16. Castilla J, Arregui L, Baleztena J, Barricarte A, Brugos A, Carpintero M et al. Incidencia de la gripe y efectividad de la vacuna antigripal en la temporada 204-2005. An Sist Sanit Navar 2006; 29: 83-92.

17. The ANZIC influenza Investigators. Critical care services and $2009 \mathrm{H} 1 \mathrm{~N} 1$ influenza in Australia and New Zealand. N Engl J Med 2009; 361: 1925-1934.

18. Castilla J, Etxeberria J, Ardanaz E, Floristán Y, López Escudero R, Guevara M. Estimating the impact of the 2009 influenza A(H1N1) pandemic on mortality in the elderly in Navarre, Spain. Euro Survell 2010; 15 (5) pii=19481.

19. Kelly H, Grant K. Interim analysis of pandemic influenza (H1N1) 2009 in Australia: surveillance trends, age of infection and effectiveness of seasonal vaccination. Euro Surveill 2009; 14: 150-154.
20. Centers for Disease Control and Prevention. Effectiveness of 2009-09 trivalent influenza vaccine against 2009 pandemic influenza A (H1N1)-United States, May-June 2009. MMWR 2009; 58: 1241-1245.

21. García-García L, Valdespino-Gómez JL, LazcanoPonce E, Jiménez-Corona A, Higuera-Iglesias A, Cruz-Hervent $P$ et al. Partial protection of seasonal trivalent inactivated vaccine against novel pandemic influenza A/H1N1 2009: case-control study in Mexico City. BMJ 2009; 339: b3928.

22. Skowronski DM, De Serres G, Crowcroft NS, Janjua NZ, Boulianne $\mathrm{N}$ et al. Association between the 2008-09 Seasonal Influenza Vaccine and Pandemic H1N1 Illness during SpringSummer 2009: Four Observational Studies from Canada. PLoS Med 2010; 7(4): e1000258. doi:10.1371/journal.pmed.1000258

23. Johansen K, Nicoll A, Ciancio BC, Kramarz P. Pandemic influenza A(H1N1) 2009 vaccines in the European Union. Euro Surveill 2009; 14: 245-251.

24. World Health Organization. Mathematical modelling of the pandemic H1N1 2009. Wkly Epidemiol Rec 2009; 84: 341-348.

25. World Health Organization. Recommended virus for influenza vaccines for use in the 2010-2011 northern hemisphere influenza. Wkly Epidemiol Rec 2010; 85: 81-92. 
